\title{
Tumor Cell Derivative Vaccine
}

National Cancer Institute

\section{Source}

National Cancer Institute. Tumor Cell Derivative Vaccine. NCI Thesaurus. Code C2341.

A vaccine made of cancer cells, parts of cancer cells, or pure tumor antigens (substances isolated from tumor cells). A tumor antigen vaccine may stimulate the body's immune system to find and kill cancer cells. 